\title{
Risk Predictors of High Uric Acid Levels Among Patients with Type-2 Diabetes
}

\author{
Zobeida Eljaaly ${ }^{1,2, *}$ \\ Muhammad Mujammami ${ }^{1-3, *}$ \\ Shaik Sarfaraz Nawaz ${ }^{3}$ \\ Mohamed Rafiullah (iD ${ }^{3}$ \\ Khalid Siddiqui iD ${ }^{3}$ \\ 'University Diabetes Center, King Saud \\ University Medical City, King Saud \\ University, Riyadh, Saudi Arabia; ${ }^{2}$ Division \\ of Endocrinology, Department of \\ Medicine, College of Medicine, King Saud \\ University, Riyadh, Saudi Arabia; \\ ${ }^{3}$ Strategic Center for Diabetes Research, \\ College of Medicine, King Saud \\ University, Riyadh, Saudi Arabia \\ *These authors contributed equally to \\ this work
}

Correspondence: Khalid Siddiqui Strategic Center for Diabetes Research, College of Medicine, King Saud University, P.O. Box 245, Riyadh, II4II, Saudi Arabia Email ksiddiqui@ksu.edu.sa
Objective: Patients with diabetes are at higher risk of the negative consequences of hyperuricemia. The objective of this study was to investigate gender and age-specific differences in the uric acid levels and to evaluate the associated risk factors among patients with diabetes.

Methods: A retrospective cross-sectional study was conducted at Strategic Center for Diabetes Research from September 2019 to January 2020, among adult type-2 diabetic patients. Serum uric acid (SUA) and several other metabolic and clinical parameters were examined. Multiple regression analysis was done to identify risk factors independently associated with hyperuricemia.

Results: A total of 433 patients were included in the analysis. SUA level was higher in males than females $(5.82 \pm 1.65 \mathrm{mg} / \mathrm{dL}$ versus $5.29 \pm 1.54 \mathrm{mg} / \mathrm{dL}, \mathrm{p}<0.001)$. The prevalence of hyperuricemia was higher in females than males $(28.8 \%$ versus $20.5 \%, \mathrm{p}=0.049)$. There was no significant difference in uric acid levels or the prevalence of hyperuricemia by age groups in the total sample or gender-stratified samples. In multivariate analysis, hyperuricemia was associated with bigger hip circumference (odds ratios [OR] were $1.03,95 \% \mathrm{CI}=$ 1.01-1.05), higher triglycerides $(\mathrm{OR}=1.005,95 \% \mathrm{CI}=1.002-1.008)$, and higher serum creatinine $(\mathrm{OR}=1.34,95 \% \mathrm{CI}=1.21-1.49)$. Hip circumference, total cholesterol, highdensity lipoprotein, and serum creatinine were independent risk factors in males, while triglycerides and higher serum creatinine were independent risk factors among females.

Conclusion: The present study demonstrates gender-specific differences in the uric acid levels and hyperuricemia prevalence. In males and females, hyperuricemia was associated with hip circumference, total cholesterol, high-density lipoprotein, triglycerides, and serum creatinine. Future large studies are needed to confirm our findings, especially in elderly females.

Keywords: uric acid, hyperuricemia, gender, diabetes, risk factors, Saudi Arabia

\section{Introduction}

Type-2 diabetes is a global public health problem of major concern, with increasing prevalence rates having almost doubled in the last three decades. ${ }^{1}$ The prevalence of type- 2 diabetes mellitus in Saudi Arabia is approximately three-folds higher as compared with the global prevalence of diabetes $(24 \%$ versus $8.3 \%) .{ }^{2,3}$ The increasing rate of diabetes in Saudi Arabia might be related to the major sociodemographic and dietary changes that occurred in Saudi Arabia during the last four to five decades. ${ }^{4}$ Moreover, some studies expected that the prevalence of type- 2 diabetes would further increase in the next decade due to high prevalence of diabetes risk factors, such as obesity and smoking among Saudi adults. ${ }^{5}$ 
Several factors can affect the levels of uric acid in humans, including genetic factors, ethnicity, age, gender, and type of diet. ${ }^{6}$ Hyperuricemia results from overproduction or decreased excretion of uric acid. ${ }^{7}$ The prevalence of hyperuricemia in the general population has been estimated between $19 \%$ and $25 \%$, with higher in males than females in the majority of reports. ${ }^{89}$ Hyperuricemia has been linked to increased risk of cardiovascular events and mortality, ${ }^{10}$ and chronic kidney disease development and progression. ${ }^{11}$ Additionally, hyperuricemia has been associated with several medical and metabolic conditions, including the different components of the metabolic syndrome. ${ }^{12,13}$ Gender-specific differences in the prevalence and risk factors of hyperuricemia have been reported. ${ }^{13,14}$ Additionally, gender is believed to further modify the associations of uric acid with glycemic control, ${ }^{15}$ cardiovascular risk factors, ${ }^{16}$ metabolic syndrome, ${ }^{17}$ and kidney disease. ${ }^{18}$ Diabetic patients are thought to be at higher risk of the negative consequences of hyperuricemia. ${ }^{19}$ In Saudi Arabia, data on the associations of hyperuricemia or uric acid levels with metabolic factors among diabetic and non-diabetic patients are limited. ${ }^{20-22}$ Additionally, gender-specific differences in such associations have never been the focus of any research. The objective of the current study was to detect gender-specific and age-specific differences in the uric acid levels and associated risk factors among patients with type- 2 diabetes.

\section{Methods}

A retrospective cross-sectional hospital-based study was conducted at the Strategic Center for Diabetes Research, College of Medicine and University Diabetes Center (UDC), King Saud University Medical City, King Saud University, Riyadh, Saudi Arabia. After submitting the research proposal to the institutional review board and getting ethical approval [No. E-19-4192], the study was conducted in accordance with the Declaration of Helsinki. An informed consent was obtained from all the type 2-diabetes patients. Medical record numbers of type-2 diabetes patients were identified from electronic health management information system. Adult type-2 diabetic patients aged 35-70 years were included, during September' 2019 and January' 2020. The current analysis excludes patients with undocumented uric acid level, active drug use (allopurinol or febuxostat), type-1 diabetes, gestational diabetes, diabetes duration $>20$ years, and patients with terminal diseases, such as cancer and organ failure. The sample size was estimated to be 433 patients provided $93 \%$ power to detect a $0.5 \mathrm{mg} / \mathrm{dL}$ difference in the uric acid level between gender and age group, assuming a mean level of $6.0 \mathrm{mg} / \mathrm{dL}$.

A structured study questionnaire was used to collect the data, which include demographic characteristics, diabetes management and complications, comorbidity, and clinical parameters like serum uric acid, blood lipids, blood pressure, serum creatinine, and blood haemoglobin.

Hyperuricemia was defined differently in males and females; serum uric acid level $>7.0 \mathrm{mg} / \mathrm{dL}(>420 \mu \mathrm{mol} /$ $\mathrm{L})$ in males and $>6.0 \mathrm{mg} / \mathrm{dL}(>360 \mu \mathrm{mol} / \mathrm{L})$ in females. ${ }^{8,23}$ According to the recommendations of the American Diabetes Association, uncontrolled blood lipids were defined as total cholesterol $>200 \mathrm{mg} / \mathrm{dL}(5.17 \mathrm{mmol} / \mathrm{L})$; low-density lipoprotein (LDL) cholesterol $>100 \mathrm{mg} / \mathrm{dL}$ ( $2.6 \mathrm{mmol} / \mathrm{L})$, high-density lipoprotein (HDL) cholesterol $<40 \mathrm{mg} / \mathrm{dL}(1.03 \mathrm{mmol} / \mathrm{L})$ in males and $<50 \mathrm{mg} / \mathrm{dL}(1.29$ $\mathrm{mmol} / \mathrm{L})$ in females, and triglycerides $>150 \mathrm{mg} / \mathrm{dL}(1.69$ $\mathrm{mmol} / \mathrm{L}$ ).

\section{Statistical Analysis}

Categorical variables were presented as frequencies and percentage, while continuous variables were presented as means and standard deviations (SD). The normal distribution of the continuous variable was done by KolmogorovSmirnov test. Differences in uric acid levels by gender and age groups were examined using Student's $t$-test and ANOVA, respectively. The prevalence of hyperuricemia was then calculated. Socio-demographic characteristics, diabetes management and complications, comorbidity, and other clinical parameters were compared between patients with and without hyperuricemia. Chi-square or Fisher's exact test, as appropriate, were used to detect significant differences in categorical variables, while Student's $t$-test was used to detect significant differences in continuous variables. To identify factors independently associated with hyperuricemia in all patients and in each gender separately, multivariate logistic regression analysis models were run after adjusting the variables that were significantly associated with hyperuricemia in univariate analysis. All $\mathrm{P}$-values were two-tailed. $\mathrm{P}$-value $<0.05$ was considered to be significant. SPSS software (release 25.0, Armonk, NY: IBM Corp) was used for all statistical analyses.

\section{Results}

Table 1 shows the level of uric acid by different age and gender groups. The mean level of uric acid was 5.52 
Table I Uric Acid Level and the Prevalence of Hyperuricemia by Different Age and Gender Groups

\begin{tabular}{|c|c|c|c|c|c|c|}
\hline \multirow[t]{2}{*}{ Variables } & \multicolumn{3}{|c|}{ Uric Acid Level (mg/dL) } & \multicolumn{3}{|c|}{ Prevalence of Hyperuricemia } \\
\hline & Mean & SD & p-value & Number & Percentage & p-value \\
\hline \multicolumn{7}{|l|}{ Gender } \\
\hline Male & 5.82 & 1.65 & 0.001 & 39 & $20.5 \%$ & 0.049 \\
\hline Female & 5.29 & 1.54 & & 70 & $28.8 \%$ & \\
\hline Total & 5.52 & 1.61 & & 109 & $25.2 \%$ & \\
\hline \multicolumn{7}{|l|}{ Age group } \\
\hline$\leq 50$ & 5.71 & 1.77 & 0.140 & 29 & $31.2 \%$ & 0.139 \\
\hline $5 I-60$ & 5.39 & 1.59 & & 52 & $21.6 \%$ & \\
\hline$>60$ & 5.68 & 1.47 & & 28 & $28.3 \%$ & \\
\hline \multicolumn{7}{|c|}{ Male by age groups } \\
\hline$\leq 50$ & 6.05 & 1.72 & 0.549 & 12 & $30.8 \%$ & 0.201 \\
\hline $5 I-60$ & 5.72 & 1.71 & & 20 & $18.3 \%$ & \\
\hline$>60$ & 5.88 & 1.42 & & 7 & $16.7 \%$ & \\
\hline \multicolumn{7}{|c|}{ Female by age groups } \\
\hline$\leq 50$ & 5.46 & 1.78 & 0.143 & 17 & $31.5 \%$ & 0.190 \\
\hline $51-60$ & 5.11 & 1.44 & & 32 & $24.2 \%$ & \\
\hline$>60$ & 5.54 & 1.50 & & 21 & $36.8 \%$ & \\
\hline
\end{tabular}

Notes: Data with normal distribution are expressed as mean \pm standard deviation. P-value $<0.05$ indicates statistical significance.

$\pm 1.61 \mathrm{mg} / \mathrm{dL}$. It was higher in males than females $(5.82$ $\pm 1.65 \mathrm{mg} / \mathrm{dL}$ versus $5.29 \pm 1.54 \mathrm{mg} / \mathrm{dL}, \mathrm{p}<0.001)$. A total of 433 patients were included in the study, and a total of 109 patients $(25.2 \%)$ met the definition of hyperuricemia. The prevalence of hyperuricemia was higher in females than males $(28.8 \%$ versus $20.5 \%, p=0.049)$. There was no difference in uric acid levels or the prevalence of hyperuricemia by age groups in the total sample or genderstratified samples.

Table 2 shows the demographic characteristics of the patients by the hyperuricemia status. The mean age was $55.4 \pm 6.2$ years, and $56.1 \%$ of the patients were females. The mean body mass index (BMI) was $32.0 \pm 6.2 \mathrm{~kg} / \mathrm{m}^{2}$ with $56.7 \%$ of the patients considered as obese (BMI $\geq$ $30 \mathrm{~kg} / \mathrm{m}^{2}$ ). The mean waist circumference was 105.4 $\pm 14.4 \mathrm{~cm}$ with $79.0 \%$ of the patients had waist circumference $\geq 102 \mathrm{~cm}$ in male or $\geq 89 \mathrm{~cm}$ in female. Hyperuricemia was significantly associated with female gender $(\mathrm{p}=$ $0.049)$ and bigger hip circumference $(p=0.004)$. The mean duration of diabetes was $15.6 \pm 3.6$ years. The mean
HbA1c was $10.1 \pm 1.7 \%$ with the majority of the patients had $\mathrm{HbAlc} \geq 7 \%$ (96.3\%) and $\mathrm{HbAlc} \geq 8 \%$ (88.4\%). The most frequent diabetic complications were nephropathy $(57.3 \%)$, neuropathy $(49.7 \%)$, retinopathy $(47.3 \%)$, and vasculopathy $(19.3 \%)$. The medications used included oral hypoglycemic drugs only $(32.4 \%)$, insulin only $(18.1 \%)$, or both $(38.7 \%)$. Only $27.9 \%$ of the patients were on diet control, $15.9 \%$ were doing regular physical exercises, and $2.5 \%$ were smokers. Hyperuricemia was significantly associated with the presence of nephropathy $(p<0.001)$ and not using oral hypoglycemic medications $(\mathrm{p}<0.001)$.

Table 3 shows the hyperuricemia status of the patients. Approximately $70.6 \%$ of the patients had blood pressure of $>130 / 80 \mathrm{mmHg}$. The mean total cholesterol was 181.9 $\pm 44.0 \mathrm{mg} / \mathrm{dL}$ with $32 \%$ of the patients had total cholesterol of $\geq 200 \mathrm{mg} / \mathrm{dL}$. The mean LDL cholesterol was 129.7 $\pm 44.2 \mathrm{mg} / \mathrm{dL}$ with $24.0 \%$ of the patients had LDL cholesterol of $>160 \mathrm{mg} / \mathrm{dL}$. The mean HDL cholesterol was 44.8 $\pm 12.3 \mathrm{mg} / \mathrm{dL}$ with $58.2 \%$ of the patients had HDL 
Table 2 Demographic Characteristics by the Hyperuricemia Status

\begin{tabular}{|c|c|c|c|c|}
\hline \multirow[t]{2}{*}{ Variables } & \multicolumn{2}{|c|}{ Hyperuricemia } & \multirow[t]{2}{*}{ Total $(N=433)$} & \multirow[t]{2}{*}{ P-value } \\
\hline & No $(N=324)$ & Yes $(\mathbf{N}=109)$ & & \\
\hline Age (years) & $55.5 \pm 5.9$ & $54.8 \pm 6.8$ & $55.4 \pm 6.2$ & 0.288 \\
\hline$\leq 50$ & $64(19.8 \%)$ & $29(26.6 \%)$ & $93(21.5 \%)$ & 0.139 \\
\hline $5 I-60$ & $189(58.3 \%)$ & $52(47.7 \%)$ & $24 \mid(55.7 \%)$ & \\
\hline$>60$ & 71 (2I.9\%) & $28(25.7 \%)$ & 99 (22.9\%) & \\
\hline \multicolumn{5}{|l|}{ Gender } \\
\hline Male & $15 \mid(46.6 \%)$ & 39 (35.8\%) & 190 (43.9\%) & 0.049 \\
\hline Female & $173(53.4 \%)$ & $70(64.2 \%)$ & $243(56.1 \%)$ & \\
\hline Height (cm) & $160.4 \pm 9.9$ & $160.4 \pm 9.4$ & $160.4 \pm 9.7$ & 0.963 \\
\hline Weight (kg) & $81.3 \pm 16.3$ & $84.8 \pm 20.2$ & $82.2 \pm 17.4$ & 0.071 \\
\hline Body mass index (BMI) $\mathrm{kg} / \mathrm{m}^{2}$ & $31.7 \pm 5.8$ & $33.0 \pm 7.3$ & $32.0 \pm 6.2$ & 0.054 \\
\hline Non-obese $<30$ & $|4|(43.7 \%)$ & $46(42.2 \%)$ & $187(43.3 \%)$ & 0.791 \\
\hline Obese $\geq 30$ & $182(56.3 \%)$ & $63(57.8 \%)$ & $245(56.7 \%)$ & \\
\hline Hip circumference (cm) & $108.0 \pm 12.8$ & $\mid 12.1 \pm 16.8$ & $109.0 \pm 14.0$ & 0.004 \\
\hline Waist circumference $(\mathrm{cm})$ & $104.7 \pm 13.9$ & $107.3 \pm 15.8$ & $105.4 \pm 14.4$ & 0.114 \\
\hline Normal & $72(22.2 \%)$ & $19(17.4 \%)$ & $91(21.0 \%)$ & 0.288 \\
\hline High* & $252(77.8 \%)$ & $90(82.6 \%)$ & $342(79.0 \%)$ & \\
\hline Diabetes Duration (years) & $15.8 \pm 3.5$ & $15.2 \pm 3.8$ & $15.6 \pm 3.6$ & 0.121 \\
\hline Glucose (mg/dl) & $212.3 \pm 89.5$ & $216.3 \pm 95.5$ & $213.3 \pm 90.9$ & 0.856 \\
\hline HbAlc (\%) & $10.2 \pm 1.7$ & $10.0 \pm 1.8$ & $10.1 \pm 1.7$ & 0.213 \\
\hline$<7$ & II (3.4\%) & $5(4.6 \%)$ & $16(3.7 \%)$ & 0.301 \\
\hline $7-7.9$ & $22(6.8 \%)$ & $12(11.0 \%)$ & 34 (7.9\%) & \\
\hline$\geq 8$ & $290(89.8 \%)$ & $92(84.4 \%)$ & $382(88.4 \%)$ & \\
\hline \multicolumn{5}{|l|}{ Diabetic Complications } \\
\hline Nephropathy & 165 (50.9\%) & $83(76.1 \%)$ & $248(57.3 \%)$ & $<0.001$ \\
\hline Neuropathy & $156(48.1 \%)$ & 59 (54.1\%) & $215(49.7 \%)$ & 0.280 \\
\hline Retinopathy & $148(45.7 \%)$ & $57(52.3 \%)$ & 205 (47.3\%) & 0.232 \\
\hline Vasculopathy & 55 (I7.6\%) & $26(24.1 \%)$ & 81 (19.3\%) & 0.143 \\
\hline \multicolumn{5}{|l|}{ Diabetic medications } \\
\hline None & $26(8.0 \%)$ & $21(19.3 \%)$ & $47(10.9 \%)$ & $<0.001$ \\
\hline Oral hypoglycemics only & $117(36.2 \%)$ & 23 (21.1\%) & 140 (32.4\%) & \\
\hline Insulin only & 43 (I3.3\%) & $35(32.1 \%)$ & $78(18.1 \%)$ & \\
\hline Both & 137 (42.4\%) & 30 (27.5\%) & 167 (38.7\%) & \\
\hline
\end{tabular}


Table 2 (Continued).

\begin{tabular}{|c|c|c|c|c|}
\hline \multirow[t]{2}{*}{ Variables } & \multicolumn{2}{|c|}{ Hyperuricemia } & \multirow[t]{2}{*}{ Total $(N=433)$} & \multirow[t]{2}{*}{ P-value } \\
\hline & No $(N=324)$ & Yes $(N=109)$ & & \\
\hline \multicolumn{5}{|c|}{ Diet control } \\
\hline No & 234 (72.2\%) & 78 (71.6\%) & $312(72.1 \%)$ & 0.894 \\
\hline Yes & 90 (27.8\%) & 31 (28.4\%) & $|2|$ (27.9\%) & \\
\hline \multicolumn{5}{|c|}{ Regular exercise } \\
\hline No & $270(83.3 \%)$ & 94 (86.2\%) & 364 (84.1\%) & 0.473 \\
\hline Yes & 54 (16.7\%) & 15 (13.8\%) & 69 (15.9\%) & \\
\hline \multicolumn{5}{|c|}{ Smoking Status } \\
\hline No & 317 (97.8\%) & 105 (96.3\%) & 422 (97.5\%) & 0.480 \\
\hline Yes & $7(2.2 \%)$ & $4(3.7 \%)$ & II (2.5\%) & \\
\hline
\end{tabular}

Notes: Data with normal distribution are expressed as mean \pm standard deviation; frequencies and percentage. $* \geq 102 \mathrm{~cm}$ in male or $\geq 89 \mathrm{~cm}$ in female. P-value $<0.05$ indicates statistical significance.

cholesterol $<40 \mathrm{mg} / \mathrm{dL}$ in males and $<50 \mathrm{mg} / \mathrm{dL}$ in females. The mean triglyceride level was $182.3 \pm 87.5 \mathrm{mg} /$ $\mathrm{dL}$ with $58.5 \%$ of the patients had triglycerides $\geq 150 \mathrm{mg} /$ dL. Approximately $71.0 \%$ of the patients had hypertension, $82.6 \%$ had hyperlipidemia, $20.5 \%$ had thyroid disease, and $35.1 \%$ had anemia. Hyperuricemia was significantly associated with higher systolic blood pressure $(\mathrm{p}=0.002)$, higher total cholesterol $(\mathrm{p}=0.021)$, lower HDL cholesterol $(p=0.015)$, higher triglycerides $(p<0.001)$, lower hemoglobin $(\mathrm{p}<0.001)$, higher serum creatinine $(\mathrm{p}<0.001)$, and history of hypertension $(\mathrm{p}=0.019)$, and thyroid disease $(\mathrm{p}=0.026)$.

Table 4 shows the potential predictors of hyperuricemia in all patients using univariate and multivariate logistic regression analysis. In multivariate analysis, the following factors were significantly associated with hyperuricemia; bigger hip circumference (odds ratios [OR] was $1.03,95 \% \mathrm{CI}=1.01-1.05, \mathrm{p}=0.001)$, higher triglycerides $(\mathrm{OR}=1.005,95 \% \mathrm{CI}=1.002-1.008, \mathrm{p}=0.002)$, and higher serum creatinine $(\mathrm{OR}=1.34,95 \% \mathrm{CI}=1.21-$ $1.49, \mathrm{p}<0.001)$. The association between gender was marginally significant $(\mathrm{OR}=1.72,95 \% \mathrm{CI}=0.98-3.03$, $\mathrm{p}=0.061)$. Adjusted $\mathrm{R}$ square for the multivariate logistic regression model was 0.309 .

Table 5 shows the potential predictors of hyperuricemia using multivariate logistic regression analysis in both males and females. The following four factors were significantly associated with hyperuricemia in males: bigger hip circumference $(\mathrm{OR}=1.05,95 \% \mathrm{CI}=1.01-1.09, \mathrm{p}=$ $0.008)$, higher total cholesterol $(\mathrm{OR}=1.01,95 \% \mathrm{CI}=$ 1.00-1.02, $\mathrm{p}=0.045)$, lower HDL cholesterol $(\mathrm{OR}=$ $3.04,95 \% \mathrm{CI}=1.20-7.72, \mathrm{p}=0.019)$, and higher serum creatinine $(\mathrm{OR}=1.30,95 \% \mathrm{CI}=1.13-1.51, \mathrm{p}<0.001)$. The following two factors were significantly associated with hyperuricemia in females: higher triglycerides (OR $=1.01,95 \% \mathrm{CI}=1.00-1.02, \mathrm{p}=0.012)$ and higher serum creatinine $(\mathrm{OR}=1.53,95 \% \mathrm{CI}=1.31-1.78, \mathrm{p}<0.001)$.

\section{Discussion}

The current study is considered the first local study to comprehensively examine the gender-specific differences in the level of uric acid and its risk factors. The current prevalence of hyperuricemia (25\%) was considered slightly higher than the general population $(21 \%),{ }^{8,9}$ but lower than reported among patients with diabetes (32\%). ${ }^{24}$ The current findings showed higher uric acid level in males than females, but a higher prevalence of hyperuricemia in females than in males. This high prevalence is mainly due to the high frequency of hyperuricemia in females (28.8\%) and males (20.5\%) also reported in other studies. ${ }^{25}$ Several studies reported higher uric acid level and/or hyperuricemia in males than females. ${ }^{8}$ However, a number of studies failed to show a higher burden in males ${ }^{9,12}$ or even showed a higher burden in females. $^{13,24}$ It has been suggested that females after menopause may experience progressively higher uric 
Table 3 Clinical Characteristics by the Hyperuricemia Status

\begin{tabular}{|c|c|c|c|c|}
\hline \multirow[t]{2}{*}{ Variables } & \multicolumn{2}{|c|}{ Hyperuricemia } & \multirow[t]{2}{*}{ Total $(N=433)$} & \multirow[t]{2}{*}{ P-value } \\
\hline & No $(N=324)$ & Yes $(N=109)$ & & \\
\hline \multicolumn{5}{|l|}{ Blood pressure $(\mathrm{mmHg})$} \\
\hline Systolic, mean $\pm S D$ & $137.2 \pm 2 \mid .3$ & $144.8 \pm 21.9$ & $139.1 \pm 2 \mid .7$ & 0.002 \\
\hline Diastolic, mean $\pm S D$ & $74.2 \pm 11.5$ & $72.1 \pm 12.6$ & $73.7 \pm 11.8$ & 0.110 \\
\hline$>130 / 80$ & $219(68.2 \%)$ & $83(77.6 \%)$ & $302(70.6 \%)$ & 0.066 \\
\hline \multicolumn{5}{|l|}{ Total cholesterol (mg/dL) } \\
\hline Mean \pm SD & $179.1 \pm 43.1$ & $190.4 \pm 45.9$ & $181.9 \pm 44.0$ & 0.021 \\
\hline Normal $<200$ & 231 (71.5\%) & $62(57.4 \%)$ & $293(68.0 \%)$ & 0.007 \\
\hline High $\geq 200$ & $92(28.5 \%)$ & $46(42.6 \%)$ & $138(32.0 \%)$ & \\
\hline \multicolumn{5}{|l|}{ LDL cholesterol (mg/dL) } \\
\hline Mean $\pm S D$ & $129.9 \pm 43.0$ & $128.8 \pm 47.7$ & $129.7 \pm 44.2$ & 0.826 \\
\hline$<100$ & $93(28.9 \%)$ & 32 (29.9\%) & $125(29.1 \%)$ & 0.802 \\
\hline $100-130$ & 81 (25.2\%) & $30(28.0 \%)$ & III (25.9\%) & \\
\hline $13 \mid-160$ & $71(22.0 \%)$ & $19(17.8 \%)$ & $90(21.0 \%)$ & \\
\hline$>160$ & 77 (23.9\%) & $26(24.3 \%)$ & $103(24.0 \%)$ & \\
\hline \multicolumn{5}{|l|}{ HDL cholesterol (mg/dL) } \\
\hline Mean \pm SD & $45.2 \pm 11.6$ & $43.5 \pm 14.1$ & $44.8 \pm 12.3$ & 0.206 \\
\hline Normal & 145 (45.2\%) & $34(31.8 \%)$ & $179(41.8 \%)$ & 0.015 \\
\hline Low* & $176(54.8 \%)$ & $73(68.2 \%)$ & $249(58.2 \%)$ & \\
\hline \multicolumn{5}{|l|}{ Triglycerides (mg/dL) } \\
\hline Mean $\pm S D$ & $171.0 \pm 77.7$ & $216.1 \pm 105.1$ & $182.3 \pm 87.5$ & $<0.001$ \\
\hline Normal $<150$ & $150(46.4 \%)$ & $29(26.9 \%)$ & $179(4 \mid .5 \%)$ & $<0.001$ \\
\hline High $\geq 150$ & $173(53.6 \%)$ & 79 (73.1\%) & $252(58.5 \%)$ & \\
\hline Serum creatinine $(\mathrm{mg} / \mathrm{dL})$ & $1.7 \pm 2.0$ & $4.0 \pm 3.5$ & $2.3 \pm 2.6$ & $<0.001$ \\
\hline \multicolumn{5}{|l|}{ Blood hemoglobin (g/dL) } \\
\hline Mean $\pm S D$ & $13.1 \pm 2.3$ & $12.1 \pm 2.4$ & $12.8 \pm 2.3$ & $<0.001$ \\
\hline Normal & $217(69.6 \%)$ & $52(50.0 \%)$ & $269(64.7 \%)$ & $<0.001$ \\
\hline Anemia $\dagger$ & 95 (30.4\%) & $52(50.0 \%)$ & 147 (35.3\%) & \\
\hline \multicolumn{5}{|l|}{ Medical history } \\
\hline Hypertension & $217(68.0 \%)$ & 87 (79.8\%) & 304 (71.0\%) & 0.019 \\
\hline Hyperlipidemia & $272(84.2 \%)$ & $84(77.8 \%)$ & $356(82.6 \%)$ & 0.127 \\
\hline Thyroid Disease & $56(17.9 \%)$ & $30(28.0 \%)$ & $86(20.5 \%)$ & 0.026 \\
\hline
\end{tabular}

(Continued) 
Table 3 (Continued).

\begin{tabular}{|l|c|c|c|c|}
\hline \multirow{2}{*}{ Variables } & \multicolumn{2}{|c|}{ Hyperuricemia } & \multirow{2}{*}{ Total (N = 433) } & \multirow{2}{*}{ P-value } \\
\cline { 2 - 5 } & No (N = 324) & Yes (N = 109) & & \\
\hline Family History & & & $372(86.1 \%)$ & 0.359 \\
\hline Diabetes & $281(87.0 \%)$ & $91(83.5 \%)$ & $79(18.7 \%)$ & 0.610 \\
\hline Renal Disease & $57(18.2 \%)$ & $22(20.4 \%)$ & & \\
\hline
\end{tabular}

Notes: Data with normal distribution are expressed as mean \pm standard deviation; $*<40 \mathrm{mg} / \mathrm{dL}$ in male and $<50 \mathrm{mg} / \mathrm{dL}$ in female; $\dagger<13 \mathrm{~g} / \mathrm{dL}$ in male and $<12 \mathrm{~g} / \mathrm{dL}$ in female. P-value $<0.05$ indicates statistical significance.

acid levels, which may exceed those of their male counterparts, due to the diminished role of sex hormones. ${ }^{14,26}$ Consistent with that, males and females $\leq 50$ years in the current study had similar prevalence of hyperuricemia (31\%), which disproportionally changed after the age of 60 years (36.8\% in females versus $16.7 \%$ in males). Therefore, the significant proportion of patients aged $>60$ years in the current study (22.9\%) might partially explain the higher female burden. Additionally, it has been shown that the higher prevalence of hyperuricemia in females can be partially explained by the relatively higher burden of cardiovascular risk factors in women after menopause as compared with men. ${ }^{13,24}$ The uric acid level and the rate of hyperuricemia increased significantly with age in women,

Table 4 Univariate and Multivariate* Logistic Regression Analysis for Potential Predictors of Hyperuricemia in All Patients

\begin{tabular}{|c|c|c|c|c|c|c|c|c|}
\hline \multirow[t]{3}{*}{ Variables } & \multicolumn{4}{|c|}{ Univariate Analysis ( $N=433)$} & \multicolumn{4}{|c|}{ Multivariate Analysis $(\mathbf{N}=375) \dagger$} \\
\hline & \multirow[t]{2}{*}{ Odds Ratio (OR) } & \multicolumn{2}{|c|}{$\begin{array}{l}\text { 95\% Confidence } \\
\text { Interval of OR }\end{array}$} & \multirow[t]{2}{*}{ P-value } & \multirow[t]{2}{*}{ Odds Ratio (OR) } & \multicolumn{2}{|c|}{$\begin{array}{l}95 \% \text { Confidence } \\
\text { Interval of OR }\end{array}$} & \multirow[t]{2}{*}{ P-value } \\
\hline & & Lower & Upper & & & Lower & Upper & \\
\hline Female compared with male & 1.57 & 1.00 & 2.45 & 0.050 & 1.72 & 0.98 & 3.03 & 0.061 \\
\hline Hip circumference $(\mathrm{cm})$ & 1.02 & 1.01 & 1.04 & 0.010 & 1.03 & 1.01 & 1.05 & 0.001 \\
\hline Systolic blood pressure $(\mathrm{mmHg})$ & 1.02 & 1.01 & 1.03 & 0.002 & & & & \\
\hline Total cholesterol (mg/dL) & 1.01 & 1.00 & 1.01 & 0.022 & & & & \\
\hline Triglycerides (mg/dL) & 1.01 & 1.00 & 1.01 & $<0.001$ & 1.005 & 1.002 & 1.008 & 0.002 \\
\hline Low HDL cholesterol $(\mathrm{mg} / \mathrm{dL}){ }^{\ddagger}$ & 1.77 & 1.11 & 2.81 & 0.016 & 1.74 & 0.99 & 3.07 & 0.054 \\
\hline Serum creatinine $(\mathrm{mg} / \mathrm{dL})$ & 1.33 & 1.23 & $\mathrm{I} .44$ & $<0.001$ & 1.34 & 1.21 & 1.49 & $<0.001$ \\
\hline Blood hemoglobin ( $g / d L)$ & 0.84 & 0.76 & 0.92 & $<0.001$ & & & & \\
\hline Hypertension & 1.86 & 1.10 & 3.14 & 0.020 & & & & \\
\hline Thyroid Disease & 1.78 & 1.07 & 2.97 & 0.027 & & & & \\
\hline Diabetic Nephropathy & 3.08 & 1.88 & 5.03 & $<0.001$ & & & & \\
\hline \multicolumn{9}{|l|}{ Diabetic medications } \\
\hline Oral hypoglycemics only & 0.24 & 0.12 & 0.50 & $<0.001$ & & & & \\
\hline Insulin only & 1.01 & 0.49 & 2.09 & 0.983 & & & & \\
\hline Both & 0.27 & 0.14 & 0.55 & $<0.001$ & & & & \\
\hline
\end{tabular}

Notes: *Multivariate logistic regression was done using backward elimination. Adjusted R square $=0.309$. $†$ Multivariate logistic regression was adjusted for gender, hip circumference, systolic blood pressure, total cholesterol, triglycerides, HDL cholesterol, serum creatinine, blood hemoglobin, diabetic nephropathy, hypertension, thyroid disease, and diabetic medications. ${ }^{\ddagger}$ Low HDL cholesterol was defined as $<40 \mathrm{mg} / \mathrm{dL}$ in male and $<50 \mathrm{mg} / \mathrm{dL}$ in female. P-value $<0.05$ indicates statistical significance. 
Table 5 Multivariate* Logistic Regression Analysis for Potential Predictors of Hyperuricemia by Gender $(\mathrm{N}=375)$

\begin{tabular}{|c|c|c|c|c|c|c|c|c|}
\hline \multirow[t]{3}{*}{ Variables } & \multicolumn{4}{|c|}{ Males $(N=167)$} & \multicolumn{4}{|c|}{ Females $(N=208)$} \\
\hline & \multirow[t]{2}{*}{ Odds Ratio (OR) } & \multicolumn{2}{|c|}{$\begin{array}{l}\text { 95\% Confidence } \\
\text { Interval of OR }\end{array}$} & \multirow[t]{2}{*}{ P-value } & \multirow[t]{2}{*}{ Odds Ratio (OR) } & \multicolumn{2}{|c|}{$\begin{array}{l}\text { 95\% Confidence } \\
\text { Interval of OR }\end{array}$} & \multirow[t]{2}{*}{ P-value } \\
\hline & & Lower & Upper & & & Lower & Upper & \\
\hline Hip circumference $(\mathrm{cm})$ & 1.05 & 1.01 & 1.09 & 0.008 & 1.02 & 1.00 & 1.05 & 0.067 \\
\hline Total cholesterol (mg/dL) & 1.01 & 1.00 & 1.02 & 0.045 & & & & \\
\hline Triglycerides (mg/dL) & & & & & 1.01 & 1.00 & 1.01 & 0.012 \\
\hline Low HDL cholesterol $(\mathrm{mg} / \mathrm{dL})^{\dagger}$ & 3.04 & 1.20 & 7.72 & 0.019 & & & & \\
\hline Serum creatinine $(\mathrm{mg} / \mathrm{dL})$ & 1.30 & 1.13 & 1.51 & $<0.001$ & 1.53 & 1.31 & 1.78 & $<0.001$ \\
\hline
\end{tabular}

Notes: Adjusted R square $=0.291$ for males and 0.380 for females. *Multivariate logistic regression was done using backward elimination. Multivariate logistic regression was adjusted for hip circumference, systolic blood pressure, total cholesterol, triglycerides, HDL cholesterol, serum creatinine, blood hemoglobin, diabetic nephropathy, hypertension, thyroid disease, and diabetic medications. 'Low HDL cholesterol was defined as $<40 \mathrm{mg} / \mathrm{dL}$ in male and $<50 \mathrm{mg} / \mathrm{dL}$ in female. P-value $<0.05$ indicates statistical significance.

while the rate of hyperuricemia showed a downward trend with age in male. There was a significant correlation between uric acid, hyperuricemia, and coronary artery disease only in female, but not in men. ${ }^{26}$ Finally, the discrepancy between gender-specific uric acid level and hyperuricemia observed in the current study may be explained by the lower cut point to meet the definition of hyperuricemia in females than males; $>6.0 \mathrm{mg} / \mathrm{dL}$ in females versus $>7.0 \mathrm{mg} / \mathrm{dL}$ in males. ${ }^{8,23}$

In addition to gender, the univariate analysis in the current study showed that hyperuricemia is associated with several risk factors, mainly traditional cardiovascular risk factors, impaired kidney function, and diabetic nephropathy. Similarly, several studies pointed to the association of hyperuricemia with cardiovascular risk factors, especially those of metabolic syndrome and impaired kidney function. ${ }^{13,14,27}$ The current findings showed that hip obesity, higher triglycerides, and higher serum creatinine were independent predictors of hyperuricemia irrespective of gender. Similarly, previous longitudinal studies showed that higher levels of triglycerides and serum creatinine predicted the development of hyperuricemia in multivariate analysis. ${ }^{26}$ Additionally, higher levels of triglycerides and different types of obesity were associated with hyperuricemia in adjusted analysis. ${ }^{14}$

The current study showed some gender differences in the risk factors of hyperuricemia. They were related to the type of dyslipidemia, triglycerides in females, and total and HDL cholesterol in males. Previous studies showed that triglycerides, cholesterol, and several other metabolic factors were associated with hyperuricemia in both males and females even in adjusted models. ${ }^{12,14,28}$ It has been suggested that the gender difference in uric acid level is influenced by several factors, such as age, sex hormones, and metabolic syndrome. ${ }^{13}$ Similar to previous studies, serum creatinine in the current study was associated with hyperuricemia in both males and females. ${ }^{27}$ It has been reported that patients with diabetes are at greater risk for the negative impact of hyperuricemia on renal function. ${ }^{29}$ However, as the current study had a cross-sectional design, it is not clear if hyperuricemia resulted in impaired renal function ${ }^{11}$ or impaired renal function resulted in impaired clearance of uric acid from the blood and hyperuricemia. ${ }^{30}$ Recently, xanthine oxidase enzyme activity and uric acid levels are shown to influence albuminuria in diabetes patients and also in the progression of nephropathy. ${ }^{31}$ Mechanisms to understand the relationship between xanthine oxidase, uric acid and albuminuria are needed to be explained.

The current study is the first local study to focus on gender-specific differences in the prevalence and risk factors of hyperuricemia. The study examined a large number of metabolic factors using both univariate and multivariate analysis. Nevertheless, some limitations are acknowledged. The cross-sectional design can prove associations but not causations. Although all the study subjects were on similar antidiabetic therapy, previous study demonstrated that patients taking diuretics had higher uric acid and carried a risk of cardiovascular events. ${ }^{32}$ In our study, the confounding effects of antidiabetic and antihypertensive therapies on uric acid 
levels were not studied. To eliminate laboratory biases, we ran a previously validated assay. Additionally, since the current data represented a single-center experience, caution should be exerted in generalizing the current findings.

\section{Conclusion}

We are reporting higher uric acid level in males than in females and a higher prevalence of hyperuricemia in females than in males. Among several risk factors detected using univariate analysis, hip circumference, higher triglycerides, and higher serum creatinine were independent predictors of hyperuricemia irrespective of gender. Modest gender differences in the risk factors of hyperuricemia were observed, triglycerides in females, and total cholesterol, HDL cholesterol in males. The current findings indicate that assessment of uric acid in patients with diabetes should be gender-specific, and risk factors for hyperuricemia need to be considered.

\section{Data-Sharing Statement}

The data set will not be shared, to protect participants' identities, but available from the corresponding author on reasonable request.

\section{Ethical Approval}

Ethical approval [No. E-19-4192] was obtained from the Institutional review Board, College of Medicine, King Saud University. An informed consent was obtained from all the type 2-diabetes patients. Medical record numbers of type-2 diabetes patients were identified from electronic health management information system.

\section{Acknowledgments}

The author would like to acknowledge the Strategic Center for Diabetes Research that is funded by the National Plan for Science, Technology, and Innovation (MAARIFAH), King Abdul-Aziz City for Science and Technology, Kingdom of Saudi Arabia. We would also like to thank the University Diabetes Center, King Saud University Medical City (KSUMC), King Saud University for patient recruitment and assistance for clinical data entry to Nourhan Mohamed Ragaee Shamardal for completing this work. Zobeida Eljaaly and Muhammad Mujammami are considered co-first authors.

\section{Funding}

This research has received financial support from the University Diabetes Center, King Saud University Medical City (KSUMC), King Saud University for consumable for this study. The authors had full responsibility for data collection, data interpretation and writing of the report. The funding source had no role in the study design, data collection, data analysis, data interpretation, writing of the report or the decision to submit for publication.

\section{Disclosure}

The authors report no conflicts of interest in this work.

\section{References}

1. World Health Organization. Global report on diabetes. Available from: https://www.who.int/publications-detail-redirect /9789241565257. Accessed June 2, 2021.

2. Al-Nozha MM, Al-Maatouq MA, Al-Mazrou YY, et al. Diabetes mellitus in Saudi Arabia. Saudi Med J. 2004;25(11):1603-1610.

3. Guariguata L, Whiting DR, Hambleton I, Beagley J, Linnenkamp U, Shaw JE. Global estimates of diabetes prevalence for 2013 and projections for 2035. Diabetes Res Clin Pract. 2014;103 (2):137-149. doi:10.1016/j.diabres.2013.11.002

4. Tourkmani A, Hassali M, Alrasheedy A, Aljadhey H, Alharbi T. Diabetes mellitus in Saudi Arabia: a major public health concern. Australas Med J. 2014;7:429-431.

5. Al-Quwaidhi AJ, Pearce MS, Sobngwi E, Critchley JA, O'Flaherty M. Comparison of type 2 diabetes prevalence estimates in Saudi Arabia from a validated Markov model against the International Diabetes Federation and other modelling studies. Diabetes Res Clin Pract. 2014;103(3):496-503. doi:10.1016/j.diabres.2013.12.036

6. Beydoun MA, Canas J-A, Fanelli-Kuczmarski MT, Tajuddin SM, Evans MK, Zonderman AB. Genetic risk scores, sex and dietary factors interact to alter serum uric acid trajectory among African-American urban adults. Br J Nutr. 2017;117(5):686-697. doi:10.1017/S0007114517000411

7. Glantzounis GK, Tsimoyiannis EC, Kappas AM, Galaris DA. Uric acid and oxidative stress. Curr Pharm Des. 2005;11(32):4145-4151. doi: $10.2174 / 138161205774913255$

8. Liu B, Wang T, Zhao HN, et al. The prevalence of hyperuricemia in China: a meta-analysis. BMC Public Health. 2011;11(1):832. doi:10.1186/1471-2458-11-832

9. Zhu Y, Pandya BJ, Choi HK. Prevalence of gout and hyperuricemia in the US general population: the national health and nutrition examination survey 2007-2008. Arthritis Rheum. 2011;63(10):3136-3141. doi:10.1002/art.30520

10. Ilundain-González AI, Gimeno-Orna JA, Sáenz-Abad D, PonsDolset J, Cebollada-Del Hoyo J, Lahoza-Pérez MDC. Impact of uric acid levels on the risk of long-term cardiovascular mortality in patients with type 2 diabetes mellitus. Endocrinol Diabetes Nutr. 2018;65(6):335-341. doi:10.1016/j.endinu.2018.01.004

11. Kuwata H, Okamura S, Hayashino Y, Ishii H, Tsujii S. Serum uric acid levels are associated with a high risk of rapid chronic kidney disease progression among patients with type 2 diabetes: a prospective cohort study [Diabetes Distress and Care Registry at Tenri (DDCRT 12)]. Diabetol Int. 2016;7(4):352-360. doi:10.1007/s13340-016-0254-2 
12. Qi D, Liu J, Wang C, et al. Sex-specific differences in the prevalence of and risk factors for hyperuricemia among a low-income population in China: a cross-sectional study. Postgrad Med. 2020;132 (6):559-567. doi:10.1080/00325481.2020.1761133

13. Redon P, Maloberti A, Facchetti R, et al. Gender-related differences in serum uric acid in treated hypertensive patients from central and east European countries: findings from the blood pressure control rate and CArdiovascular Risk profilE study. J Hypertens. 2019;37 (2):380-388. doi:10.1097/HJH.0000000000001908

14. Yu S, Yang H, Guo X, et al. Prevalence of hyperuricemia and its correlates in rural Northeast Chinese population: from lifestyle risk factors to metabolic comorbidities. Clin Rheumatol. 2016;35 (5):1207-1215. doi:10.1007/s10067-015-3051-6

15. Kawamoto R, Ninomiya D, Kasai Y, et al. Interaction between gender and uric acid on hemoglobin A1c in community-dwelling persons. $J$ Endocrinol Invest. 2018;41(4):421-429. doi:10.1007/s40618-0170760-5

16. Rodrigues SL, Baldo MP, Capingana P, et al. Gender distribution of serum uric acid and cardiovascular risk factors: population based study. Arq Bras Cardiol. 2012;98(1):13-21. doi:10.1590/s0066$782 \times 2011005000116$

17. Krzystek-Korpacka M, Patryn E, Kustrzeba-Wojcicka I, Chrzanowska J, Gamian A, Noczynska A. Gender-specific association of serum uric acid with metabolic syndrome and its components in juvenile obesity. Clin Chem Lab Med. 2011;49(1):129-136. doi:10.1515/CCLM.2011.011

18. Yang Y, Zhou W, Wang Y, Zhou R. Gender-specific association between uric acid level and chronic kidney disease in the elderly health checkup population in China. Ren Fail. 2019;41(1):197-203. doi:10.1080/0886022X.2019.1591994

19. Xu Y, Zhu J, Gao L, et al. Hyperuricemia as an independent predictor of vascular complications and mortality in type 2 diabetes patients: a meta-analysis. PLoS One. 2013;8(10):e78206. doi:10.1371/journal. pone.0078206

20. Rafiullah M, Siddiqui K, Al-Rubeaan K. Association between serum uric acid levels and metabolic markers in patients with type 2 diabetes from a community with high diabetes prevalence. Int $J$ Clin Pract. 2020;74(4):e13466. doi:10.1111/ijcp.13466

21. Al-Arfaj AS. Hyperuricemia in Saudi Arabia. Rheumatol Int. 2001;20 (2):61-64. doi:10.1007/s002960000076
22. De Cosmo S, Viazzi F, Pacilli A, et al. Serum uric acid and risk of CKD in type 2 diabetes. Clin J Am Soc Nephrol. 2015;10 (11):1921-1929. doi:10.2215/CJN.03140315

23. Wang J, Qin T, Chen J, et al. Hyperuricemia and risk of incident hypertension: a systematic review and meta-analysis of observational studies. PLoS One. 2014;9(12):e114259. doi:10.1371/journal. pone. 0114259

24. Wang J, Chen R-P, Lei L, et al. Prevalence and determinants of hyperuricemia in type 2 diabetes mellitus patients with central obesity in Guangdong Province in China. Asia Pac J Clin Nutr. 2013;22 (4):590-598. doi:10.6133/apjen.2013.22.4.16

25. Maloberti A, Qualliu E, Occhi L, et al. Hyperuricemia prevalence in healthy subjects and its relationship with cardiovascular target organ damage. Nutr Metab Cardiovasc Dis. 2021;31(1):178-185. doi:10.1016/j.numecd.2020.08.015

26. Sun Y, Zhang H, Tian W, et al. Association between serum uric acid levels and coronary artery disease in different age and gender: a cross-sectional study. Aging Clin Exp Res. 2019;31(12):1783-1790. doi:10.1007/s40520-019-01137-2

27. Ni Q, Lu X, Chen C, Du H, Zhang R. Risk factors for the development of hyperuricemia: a STROBE-compliant cross-sectional and longitudinal study. Medicine. 2019;98(42):e17597. doi:10.1097/ MD.0000000000017597

28. Cui L, Meng L, Wang G, et al. Prevalence and risk factors of hyperuricemia: results of the Kailuan cohort study. Mod Rheumatol. 2017;27(6):1066-1071. doi:10.1080/14397595.2017.1300117

29. Fouad M, Fathy H, Zidan A. Serum uric acid and its association with hypertension, early nephropathy and chronic kidney disease in type 2 diabetic patients. J Bras Nefrol. 2016;38(4):403-410. doi:10.5935/ 0101-2800.20160065

30. Prasad Sah OS, Qing YX. Associations between hyperuricemia and chronic kidney disease: a review. Nephrourol Mon. 2015;7(3): e27233. doi:10.5812/numonthly.7(3)2015.27233

31. Klisic A, Kocic G, Kavaric N, Jovanovic M, Stanisic V, Ninic A. Xanthine oxidase and uric acid as independent predictors of albuminuria in patients with diabetes mellitus type 2. Clin Exp Med. 2018;18(2):283-290. doi:10.1007/s10238-017-0483-0

32. Maloberti A, Bombelli M, Facchetti R, et al. Relationships between diuretic-related hyperuricemia and cardiovascular events: data from the URic acid Right for heArt Health study. J Hypertens. 2021;39 (2):333-340. doi:10.1097/HJH.0000000000002600

\section{Publish your work in this journal}

Diabetes, Metabolic Syndrome and Obesity: Targets and Therapy is an international, peer-reviewed open-access journal committed to the rapid publication of the latest laboratory and clinical findings in the fields of diabetes, metabolic syndrome and obesity research. Original research, review, case reports, hypothesis formation, expert opinion and commentaries are all considered for publication. The manuscript management system is completely online and includes a very quick and fair peer-review system, which is all easy to use. Visit http://www.dovepress.com/testimonials.php to read real quotes from published authors.

Submit your manuscript here: https://www.dovepress.com/diabetes-metabolic-syndrome-and-obesity-targets-and-therapy-journal 